\title{
Review of current approaches to spatially explicit urban vulnerability assessments: hazard complexity, data sources, and cartographic representations
}

\author{
Pavel Raška ${ }^{1 凶}-$ Martin Dolejš $^{1}-$ Jan Pacina $^{2}-$ Jan Popelka $^{2}-$ Jan Píša $^{1}-$ \\ Kristýna Rybová ${ }^{1}$ \\ ${ }^{1}$ Department of Geography, Faculty of Science, J. E. Purkyně University in Ústí nad Labem, Czechia \\ ${ }^{2}$ Department of Geoinformatics, Faculty of Environment, J. E. Purkyně University in Ústí nad Labem, Czechia \\ $\bowtie$ pavel.raska@ujep.cz
}

\begin{abstract}
Socio-ecological hazards are processes that - depending on the vulnerability of societal systems - may have profound adverse impacts. For this reason, the current discourse in disaster risk reduction (DRR) has been experiencing a shift toward a vulnerability-led paradigm, raising new questions about how to address (i) the complexity of vulnerabilities to multiple hazards, (ii) their cultural, dynamic, and subjective character, and (iii) the effectiveness and legitimacy of vulnerability assessments as decision-support tools. In this paper, we present a review of 707 vulnerability studies (derived from the Clarivate WoS database; 1988-2018) with a particular focus on urban settings and spatially explicit assessments in order to evaluate current efforts to meet the aforementioned issues. The reviewed studies assessed vulnerabilities to 35 hazard types that were predominantly $(\mathrm{n}=603,85 \%)$ analysed as single hazards (mostly seismic, flood, and groundwater contamination hazards, as well as climate change), whereas only $15 \%(n=104)$ of studies focused on multiple hazards (mostly atmospheric hazards). Within the spatially explicit vulnerability studies, almost $60 \%$ used data collected by the study itself (mostly seismic hazards), while statistical and combined data were both employed in $20 \%$ of cases (mostly floods, climate change, and social and political hazards). Statistical data were found to have only limited transferability, often being generalised to be applicable in small-scale studies, while reducing the role of cultural and contextual factors. Field research data provided high-resolution information, but their acquisition is time-consuming, and therefore fixed at a local scale and single temporal stage. Underlying hazard types and suitable data sources resulting in other differences found a preference towards the specific coverage and resolution of vulnerability maps that appeared in $44 \%$ of all reviewed studies. Altogether, the differences we found indicated a division of spatially explicit vulnerability research in two major directions: (i) geological and geomorphological studies focusing on physical vulnerability, using their own data surveys at a detailed scale and lacking links to other hazards, and (ii) other studies (mostly atmospheric hazards and socialpolitical hazards) focusing on social or combined vulnerabilities, using primarily statistical or combined data at a municipal, regional, and country scale with occasional efforts to integrate multiple hazards. Finally, although cartographic representations have become a frequent component of vulnerability studies, our review found only vague rationalisations for the presentation of maps, and a lack of guidelines for the interpretation of uncertainties and the use of maps as decision-support tools.
\end{abstract}

Keywords

Vulnerability

Socio-ecological hazards Disasters,

Urban,

Spatial assessment

Received: 23 April 2019

Received in revised form: 7 June 2020

Accepted:

9 June 2020 


\section{Highlights for public administration, management and planning:}

- Despite the theoretical discourse, there remains an alarming scarcity of assessments integrating vulnerabilities to multiple socio-ecological hazards.

- The data used in vulnerability studies only partly reflect the dynamic and culturally constrained character of vulnerabilities and disasters.

- We urge for better rationalisations for the presentation of vulnerability maps, and for accompanying guidelines to interpret these maps in decision-making processes.

\section{Introduction}

Socio-ecological hazards are induced by natural and human processes (or a hybrid of both), with potentially adverse impacts on societal systems. Approximately two hundreds of millions people are affected by natural hazards globally every year, while the livelihoods of hundreds of millions (the exact numbers are subject to discussions) are exposed to human and hybrid hazards related to political unrest, industrial accidents, socioeconomic shocks, pandemics, and other factors (Leaning \& GuhaSapir 2013; EM-DAT 2018). Despite interannual variations, long-term social and economic losses may continue to rise as a result of uncertainties related to climate change (Kelman 2015; Hore et al. 2018; WMO 2019) and the compound effects of political reluctance to address structural causes of issues including continuing poverty, economic injustice, and creeping changes in population health (Sawada et al. 2019). The salience of these impacts is undoubtedly affected by human occupation of hazard zones (Burton et al. 1978; Hewitt 1983) and by human interventions that affect the frequency and exacerbate the intensity of socioecological hazards through compound and cascading effects (Cutter 2018). These notions have influenced a shift in the disaster risk reduction (DRR) discourse toward a vulnerability-led paradigm in recent decades (Sarewitz et al. 2003; UNDRR 2015). Since its introduction to policy documents, vulnerability has been the tenet of DRR research, suggesting different conceptualisations (e.g., Cutter 1996; Adger 2006, see Kelman 2008 for critical reflection; Burton et al. 2018), explaining meanings (Wisner 2016; Kelman 2018), and providing reviews of vulnerability assessment methodologies (e.g., Hufschmidt 2011; de Ruiter et al. 2017). In this paper, we use the generic definition for vulnerability proposed by UNISDR (2017): 'the characteristics determined by physical, social, economic and environmental factors or processes which increase the susceptibility of an individual, a community, assets, or systems to the impacts of hazards'.
Although this shift toward vulnerability assessments is promising, it has also raised critical challenges for research agendas and for practitioners. First, it has become increasingly evident that vulnerabilities to various processes create complexities with multiple roots and eventual trade-offs (e.g., Leaning \& Guha-Sapir 2013; Rufat et al. 2015) that must be studied in a holistic manner (White et al. 2001; Turner et al. 2003; Adger 2006). This notion results from the multilevel structure and stochastic character of socio-ecological systems (Dostál 2008) exposed to hazards. For example, in 2013 the European Forum for Disaster Risk Reduction (EFDRR 2013) published a surveybased report revealing several linkages between Climate Change Adaptation (CCA) and DRR across European countries. The report included a recommendation to 'continue to strengthen the link between CCA and DRR, integrating CCA into DRR policies, plans and actions, and vice versa' with a strong emphasis laid on vulnerability assessments. However, both random samplings of current publications and overall evaluations of policy outcomes (Kelman et al. 2015; Wisner 2020) show that efforts have fallen short in acknowledging the multifaceted nature of vulnerability. This lack denotes a continuing challenge to integrate both the components of and methods for assessing vulnerability (Kuhlicke et al. 2011). Second, based on the widening conceptualisation of vulnerability as a socially constructed characteristic that is sitespecific and co-dependent on subjective probabilities (i.e. mental vulnerabilities or degrees of beliefs; Burgman 2005), current studies have increasingly called for the consideration of cultural factors and issues of power and legitimacy in assessments of vulnerability and risk reduction (Kasperson et al. 2001; Bankoff et al. 2015; Burton et al. 2018). Refocusing research on vulnerable populations and explaining the roots of their vulnerability has also raised two challenges for conventional indicator-based vulnerability assessments: (i) the liquidity of underlying information, denoting the spatiotemporal dynamics of contexts and variables that are difficult to fix and process (Raška 
Dostál 2017; Raška 2019), and (ii) the bias caused by subjective and culturally-based interpretation of underlying information by those conducting vulnerability assessments. Third, while vulnerability assessment is believed to better address the roots of disasters and provide more legitimate and just insights than solely technocratic hazard assessments, the adaptive pathways needed to transform vulnerability assessments and DRR knowledge in general into decision-supportive tools have begun only recently discussed (Munene et al. 2018; Wisner 2016, 2020). This has seemed to shift the focus of research toward creating new indicators and improving the sophistication of vulnerability assessments, rather than exploring if and how the identified vulnerability characteristics and spatiotemporal variations could be addressed in order to reduce disaster risk (Lewis 2012; Oliver-Smith et al. 2016; Kuhlicke et al. 2020).

Spatially explicit vulnerability assessments clearly exhibit all of the aforementioned challenges; we define these as assessments that explicitly monitor, explore, and report on spatial variations in vulnerabilities, frequently with the use of cartographic representation. Spatially explicit assessments (i) are conducted for a certain spatiotemporal socioecological setting and therefore should reflect interdependencies among various hazards and risks (which are increasingly spread across boundaries), (ii) tend to provide standardised and therefore comprehensive cartographic representation (thus challenging the nature of underlying data and their aggregation) (e.g. Cutter et al. 2008; Fekete 2012; Rufat et al. 2015), and (iii) intend to provide a supportive base for particular phases and actions of DRR, such as Emergency Operational Planning (Gunes \& Kovel 2000; Alexander 2002; BojóroquezTapia et al. 2009; Fekete 2012; Stehlíková et al. 2017; Horák Ivan 2019) or Humanitarian Action (Hall et al. 2008; Lechtenfeld 2013; Berg \& Emran 2020), questioning the usability of cartographic representations of vulnerabilities as well as their legitimacy, because such visual representations may lead to stigmatization of certain populations and areas (Fekete 2012).

In this paper, we explore the current state of these challenges and potential approaches to overcome them by reviewing current practices in spatially explicit vulnerability mapping. This review was not restricted to any particular hazard or risk, but rather focused on urban areas (or any supra-regions including urban areas) in which the majority of global population is concentrated ${ }^{1}$; a UN report on global cities (UN 2018: 9) noted that 679 of the 1146 cities with a population of at least half a million faced individual or combined disaster risks. Our specific research questions explored (i) the coherency of current vulnerability assessment methods and whether/how they addressed the complexity and intertwined nature of hazards with sufficient focus, (ii) which types of data have been used for map-based vulnerability assessments and how data type affects their flexibility, and (iii) the prevailing approaches (coverage, scale, and resolution) to cartographic representation of vulnerability and how these potentially hamper assessments of vulnerability to multiple hazards.

\section{Data and methods}

\subsection{Review}

Although no review can claim to be complete, we made an effort to provide transparent reporting of our individual steps (Moher et al. 2009). Based on our focus on vulnerability assessments of multiple socio-ecological hazards in urban settings, we conducted a pre-test to explore publication patterns specific to terms used primarily in titles, abstracts, and key words. The search (performed in May 2018 using the Clarivate WoS database) used the Topic (TO) and Title (TI) fields with the following words: 'urban', 'vulnerability', 'environmental', and 'risk'. Terms such as 'map' (mapping) and 'spatial assessment' were not used to narrow the search because we intended to explore the proportion of spatially explicit vulnerability assessments in all studies. Within this pre-test, random publications from each group of results (Table 1) were screened for content, after which we decided to use a combination of the search terms TO: urban and TI: vulnerability.

The 1098 records identified using these terms were then subject to the step-wise evaluation schematically shown in a PRISMA flow chart in Fig. 1. To maintain consistency and intercoder reliability during record evaluation, screening was conducted in two steps. First, all authors (coders) went through all records and marked considered candidates for exclusion. Second, we focused on 223 exclusion candidates (records marked by at least two coders), then checked these again, resulting in 149 records being excluded from the dataset.

In the next step, all records were evaluated for eligibility to comply with the review's goals, favouring empirical studies presenting original research and focusing on societal vulnerabilities to socioecological hazards. During this process, 240 further records were excluded for criteria listed in Table 2. 
Table 1 Combinations of search words used in the Clarivate WoS database (May 2018) during the pre-test stage of the review

\begin{tabular}{|c|c|c|}
\hline Key words & $\begin{array}{l}\text { Number } \\
\text { of } \\
\text { records }\end{array}$ & Comments on content \\
\hline $\begin{array}{l}\text { TO: urban } \\
\text { TO: vulnerability }\end{array}$ & 4568 & $\begin{array}{l}\text { Vulnerability frequently menti- } \\
\text { oned only in the abstract as } \\
\text { a framing concept }\end{array}$ \\
\hline $\begin{array}{l}\text { TO: urban } \\
\text { TO: vulnerability } \\
\text { TO: environmental }\end{array}$ & 886 & $\begin{array}{l}\text { The search generally under- } \\
\text { estimated social vulnerability }\end{array}$ \\
\hline $\begin{array}{l}\text { TO: urban } \\
\text { TO: vulnerability } \\
\text { TO: risk }\end{array}$ & 2249 & $\begin{array}{l}\text { Included many studies indirectly } \\
\text { related to vulnerability or using } \\
\text { it onlyas a framing concept }\end{array}$ \\
\hline $\begin{array}{l}\text { TO: urban } \\
\text { TO: vulnerability } \\
\text { TO: environmental } \\
\text { TO: risk }\end{array}$ & 433 & $\begin{array}{l}\text { The search generally under- } \\
\text { counted social vulnerability; } \\
\text { the resulting number of records } \\
\text { was not representative }\end{array}$ \\
\hline $\begin{array}{l}\text { TO: urban } \\
\text { TO: risk }\end{array}$ & 48825 & $\begin{array}{l}\text { Too broad, including many } \\
\text { studies devoted to risk manage- } \\
\text { ment and adaptation; risk was } \\
\text { understood inconsistently across } \\
\text { the disciplines }\end{array}$ \\
\hline $\begin{array}{l}\text { TO: urban } \\
\text { TI: vulnerability }\end{array}$ & 1098 & $\begin{array}{l}\text { Mostly studies explicitly addre- } \\
\text { ssing vulnerability in the core text; } \\
\text { understanding of the central } \\
\text { concept seemed consistent }\end{array}$ \\
\hline $\begin{array}{l}\text { TO: urban } \\
\text { TI: risk }\end{array}$ & 10701 & $\begin{array}{l}\text { Included many studies devoted } \\
\text { to risk management and adaptation }\end{array}$ \\
\hline
\end{tabular}

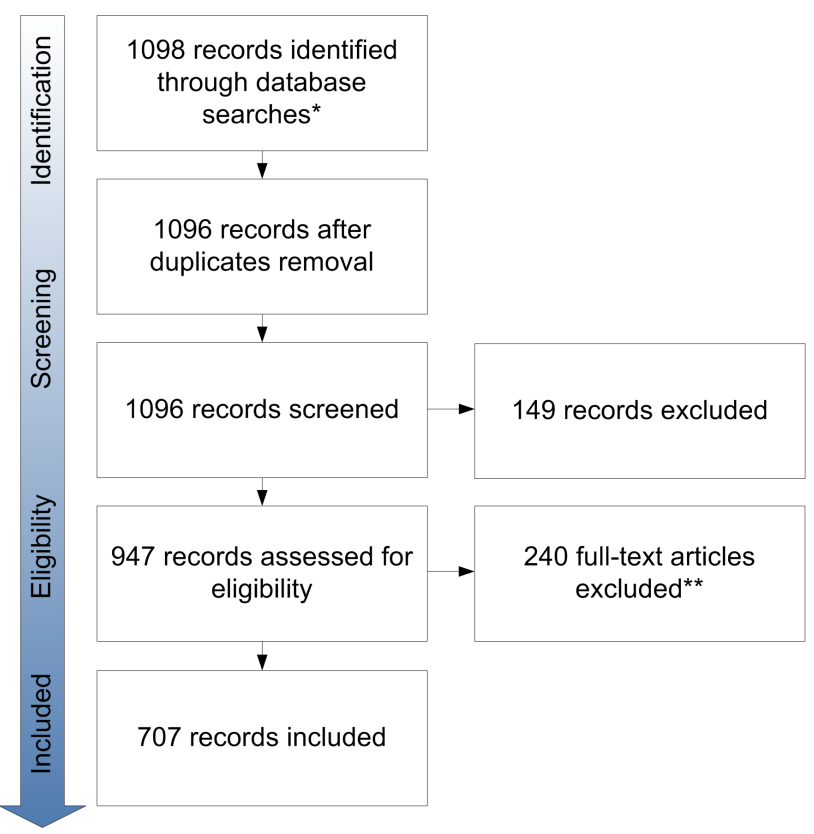

Fig. 1 Review process flow chart. Notes: *Only two duplicate records was identified as a single database was used for the review. ${ }^{* *}$ Criteria for exclusion are listed in Table 2.
Table 2 Criteria for exclusion of records within the screening and eligibility stages of the review

\section{Paper type}

- Review papers

- Commentaries and letters to editors

- Corrigendum

Data type

- Explored theoretical, conceptual, and strategic

dimensions of vulnerability

- Used experimental approach without field empirical data

\section{Object and area types}

- Focused on plant and animal species

Focused only on specific types of objects

(e.g. tunnels, shafts, special materials)

- Dealt explicitly with natural environments and ecosystems

- Explored only site-specific themes not applicable

to other areas (e.g. a slum in a selected country)

\section{Factors related to focus}

- Focused on health risks related to individual determinants and not at territorial levels

- Explored vulnerability as a characteristic specific to/in certain societal or economic segments (e.g. vulnerability of working children, sex crimes at work, price of economic products)

The final list of 707 records was evaluated by coders according to their research structure, including hazard type, country, extent of focus area (continent, country, region, semi-natural area such as floodplain, city, city part/neighbourhood, block of buildings, population segment), presence of spatially explicit evaluation, focus on cartographic visualisation, map resolution (country, region, semi-natural area such as floodplain, city, city part/neighbourhood, block of buildings, fuzzy approach - grid, linear features), explicit explanation of indicators, and major types of data sources used for indicators.

\subsection{Data aggregation and evaluation}

The records in the database were aggregated using $\mathrm{R}$ statistics (R Core Team 2017) in different ways, complying with the specific aims of the paper. First, we explored the frequency of vulnerability studies dealing with single and multiple hazards as well as connections between different hazards in multihazard studies. Along with descriptive statistics, we designed a typology of countries worldwide in terms of the prevalence of specific hazard types and the share of multi-hazard approaches to vulnerability assessments in these countries. To do so, the records were divided according to their spatial extent (country, continent, or global) and the number of hazards researched. All countries were then assigned to five pre-defined types according to the variability of approaches used to deal with single 


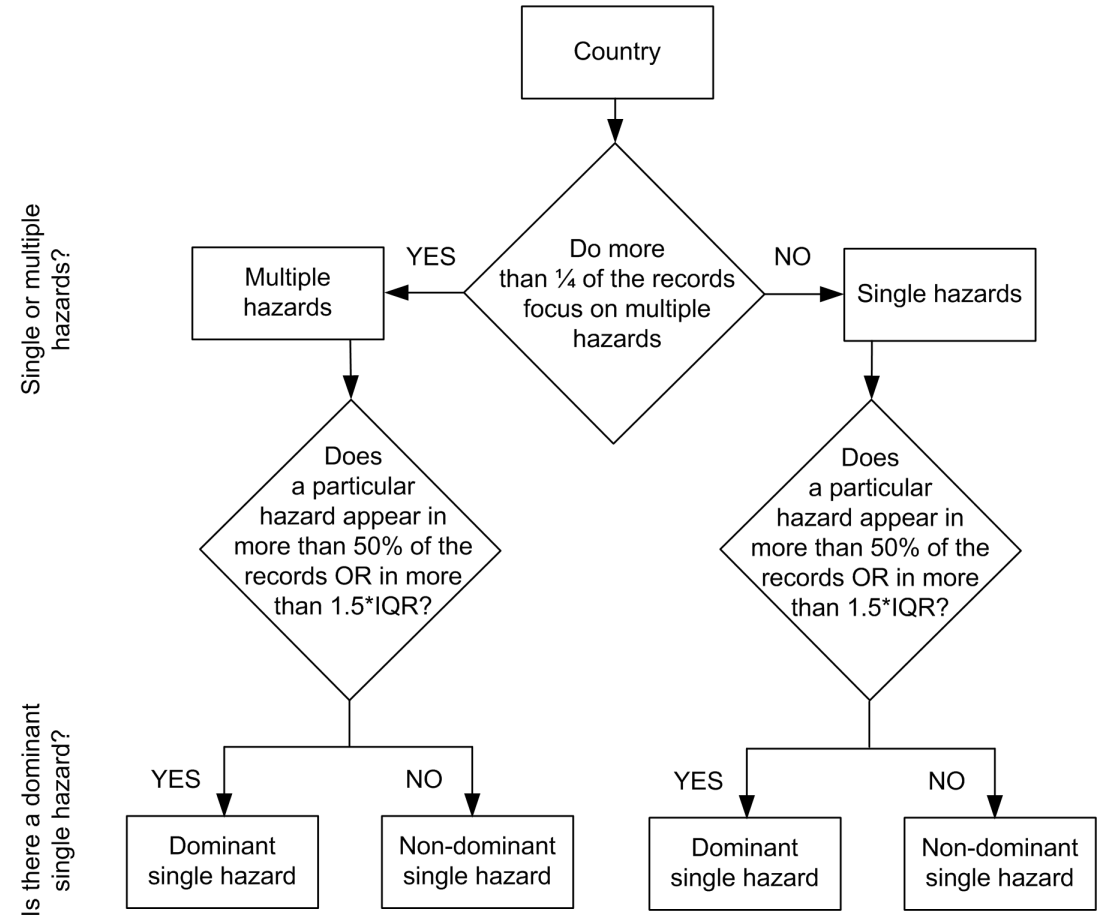

Fig. 2 Flow chart for classifying records based on the plurality and dominance of hazards researched. IQR = Inter Quartile Range

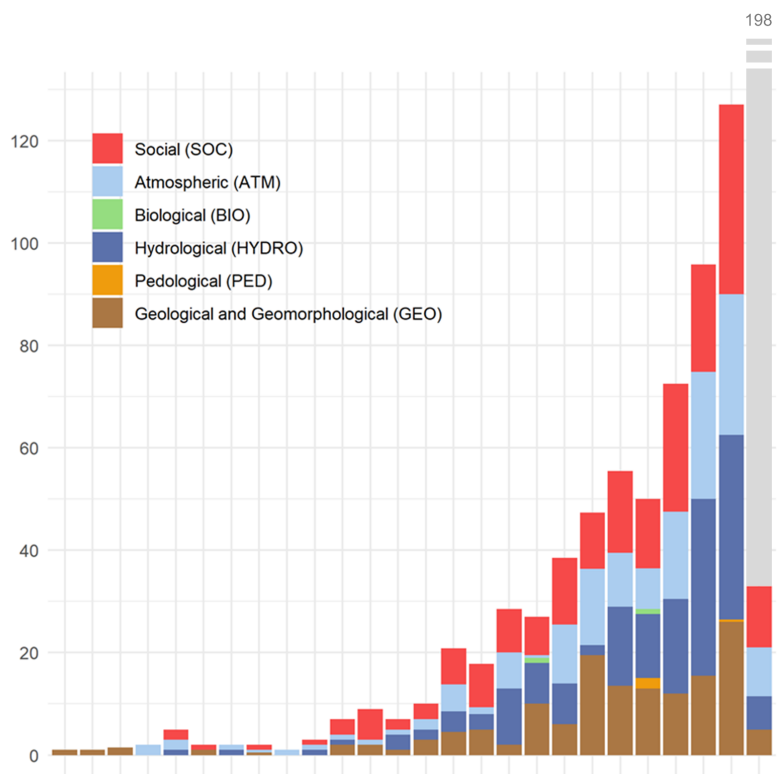

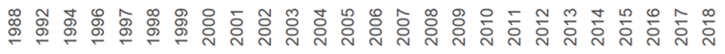

Fig. 3 Annual frequency of studies (recorded in the database) assigned to different hazard types (defined in Supplement 1). Note: the repeated check revealed exponentially increasing numbers of papers for latter half of 2018 and for 2019, yet with roughly a similar thematic structure as in the preceding years and multiple hazards (Fig. 2). Continent-scale and global studies were also assigned to the five predefined types.

Second, the data were aggregated to explore whether any pattern existed among the studied hazards in terms of the indicators used to elaborate the vulnerability assessments. Third, the records were analysed to reveal the share of spatially explicit vulnerability assessments and of cartographic representations for each hazard type. The cartographic representations were then assessed in terms of coverage and spatial resolution to determine whether any approaches to cartographic representation were prevalent for individual hazards.

\section{Results and Discussion}

\subsection{Dataset: tracing the publication produc- tion of vulnerability mapping}

The 707 selected records showed a clear trend towards increasing frequency of vulnerability studies in scholarly publishing (Fig. 3), from only a few records at the end of the 1980s to > 100 studies in 2017. Currently, there is no universally accepted classification of socio-ecological hazards of a sufficient detail (EEA 2010; MunichRe 2017; EM-DAT 


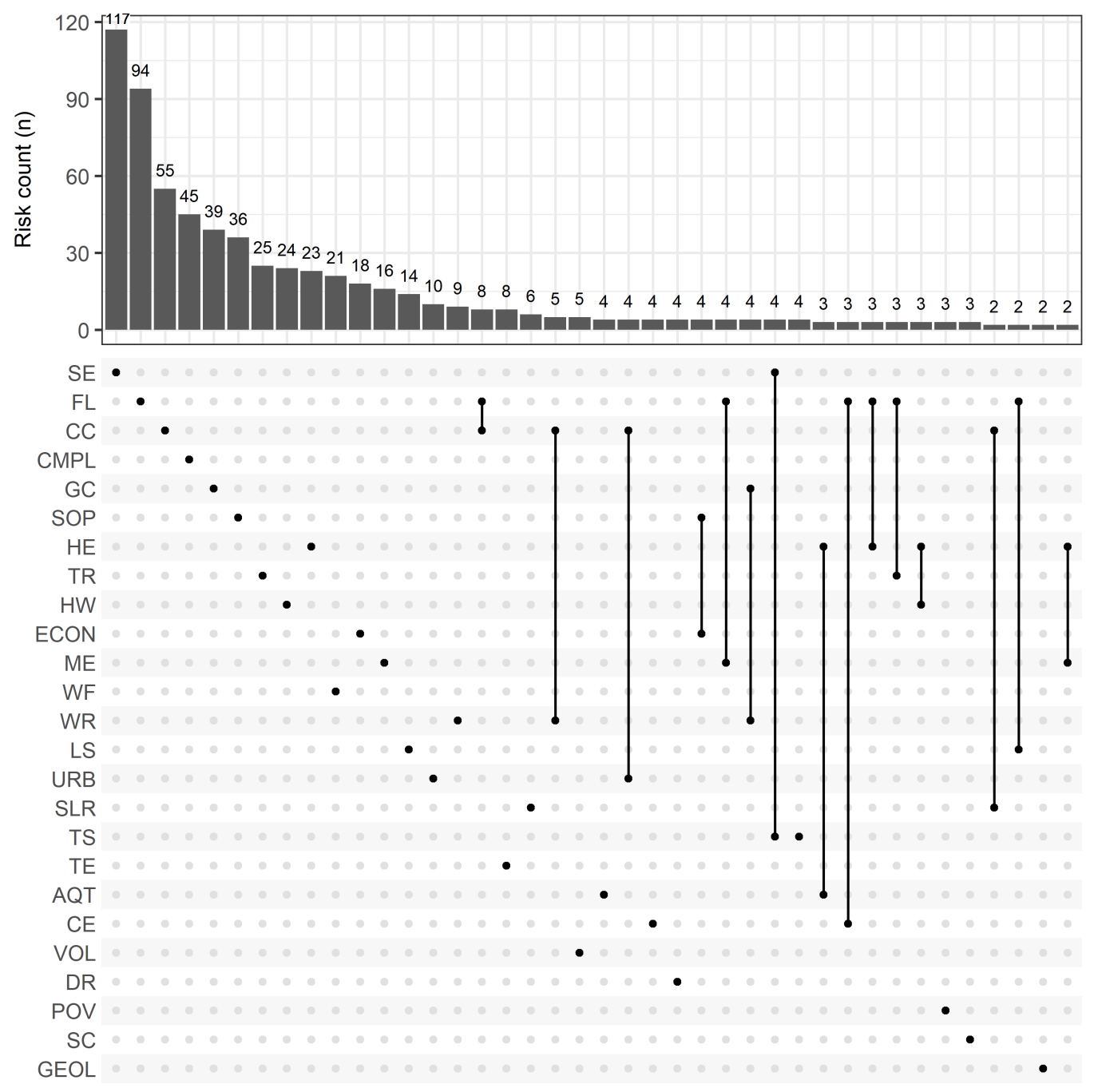

Fig. 4 Individual hazards and their combinations in vulnerability assessments within the reviewed studies. See Supplement 1 for explanation of hazard abbreviations. Note: for visual clarity, the figure displays only 40 columns accounting for 643 of the 693 records.

2018). In addition, as the use of any of the predefined classification schemes could bias the distribution of studies among the hazard and multihazard groups, we decided for an implicit classification procedure based upon the reviewed studies. We are aware that even this approach may have resulted in certain distortion of the results, i.e. in uncertainties that must be taken into account throughout the further text. For this reason, the most evident uncertainties related to particular hazard types are explained in footnotes. By content analysis and iterative re-categorisation of the records, we identified 35 hazard types, 21 of which could be tentatively ${ }^{2}$ assigned to natural and 14 to social processes (see full list in Supplement 1).

The relative share of studies dealing with particular hazard types displayed surprising invariance over time, possibly indicating either that all considered hazards maintained or even increased their severity, or that the robustness of scientific publishing platforms (i.e. variety of journals) did not fully capture certain shifts in research agendas. There was also a persistent dominance of studies devoted to natural hazards (ca. 3/4 of all reviewed studies). Given the current declared policy shift toward climate change-related socio-ecological vulnerabilities, it is quite important to determine whether there is an increasing number of studies focusing on interlinks between the hazards defined in Fig. 3. However, before exploring this question further, we should point out a recurrent terminological inconsistency revealed in the first step of the review and already mentioned in the literature (Cutter 1996). This consists of a duality in the use 
of vulnerability as both a subject- and a causereferred characteristic. While some studies explicitly define their focus on vulnerabilities of population segments, cities, habitats, and other subjects (therefore addressing rather structural roots of disasters; e.g. Lins-de-Barros 2017), the titles (and frequently the rest) of other studies assess vulnerabilities to specific hazards that are considered as causal factors (e.g. Rashed \& Weeks 2003; Chatterjea 2011). A third group of studies explicitly aimed to assess the vulnerability of certain objects or population segments to specific hazards (e.g. Singh et al. 2018). On the other hand, some studies remained vague in acknowledging their research focus in the title, abstract, or key words.

\subsection{Multi-hazard vulnerability assessments}

The analysed studies focused on 35 hazard types that appeared as single hazards or as one of 70 unique combinations. Most studies ( $\mathrm{n}=603,85 \%)$ focused on a single hazard in their vulnerability assessments. Of the remaining 15\% ( $n=104)$ multihazard studies, a vast majority focused on two hazards $(n=88)$, while only four aimed to integrate four hazards (the highest identified number). Even if studies that - according to their authors - tackled complex vulnerability assessments ${ }^{3}$ were added to this set $(n=45)$, the total share of studies integrating vulnerability assessments to multiple hazards only slightly exceeded $20 \%$ of all records $(n=149)$. Adding the similar portion that dealt solely with climate change $(n=55)$ increased the number of integrative assessments to $29 \% .{ }^{4}$ These first figures indicate that current publication practices continue to lag behind the proclaimed shift towards holistic vulnerability assessments of socio-ecological systems as shown in earlier studies (Liverman 1990; Turner et al. 2003) and reviews (Adger 2006; Thonicke et al. 2020).

Our subsequent analysis focused on hazard types and their unique combinations that were researched by at least five studies in the review database. The reduced database of 693 studies (those consisting of particular hazard type or unique hazard combinations with at least five records) included 28 hazard types, all appearing in singlehazard studies, and 25 of them in unique multihazard combinations, representing 14\% $(n=96)$ of studies in the reduced database (Fig. 4). Most of the single-hazard studies were devoted to seismic and flood hazards, followed by climate change, complex vulnerabilities, groundwater contamination, and social-political hazards. The multi-hazard studies exhibited a clear preference towards atmo- spheric hazards, combining climate change with various weather extremes, floods, and hazards to water resources, whereas seismic hazards tended to be explored most independently of other hazard types. This certainly derives from the very nature of these processes, but also indicated that certain disciplinary and epistemic traditions may affect the low number of integrative vulnerability assessments. Such assumptions reflect the findings of earlier research identifying the reluctance of professionals to undertake interdisciplinary work (Alexander 1995; Baker 2017). To explore some aspects of these assumptions, in the following sections we focus on data sources and typical spatial representations used in assessments of vulnerability to individual hazard types (thus partly denoting the disciplines engaged).

The surprisingly small number of integrative vulnerability assessments raises the question of whether certain specialisations could be influenced by the spatial scales of the studied regions, therefore increasing the probabilities of combined hazard types in individual countries. To analyse the global pattern of vulnerability studies at the country scale, we conducted a typological assessment (Fig. 5).

This global map clearly records a prevalence of studies in the Northern Hemisphere and in economically developed countries. Given current urbanisation trends and differences in livelihood among the global population, the focal areas of empirical vulnerability research continue to miss the spatial distribution of populations under threat (Alexander 1995; OECD 2019). Such claim is difficult to confirm by comparison with annual reports on disaster events (MunichRe 2017), since they are primarily based on reporting of economic (both insured and not insured) losses. For 2016, for instance, the report indicates only three events in Africa to be among the largest 50 loss events. The regional frequencies of disasters (both $\mathrm{Mu}$ nichRe 2017 and EM-DAT 2018) provide a better insight, showing almost equal distribution of geophysical, climatic, biological as well as technological hazards worldwide. Yet, the annual reports still do not acknowledge variations of social capacities to cope with disrupting events. The prevailing focus of vulnerability assessments on some regions may be driven by the spatial accessibility of regions and data availability, favouring research in researchers' domestic countries since most research consists of local case studies. At the same time, this trend suggests that vulnerability assessments prevailingly focus on areas with potentially high economic losses, in line with a monetisation ap- 


\section{sciendo}

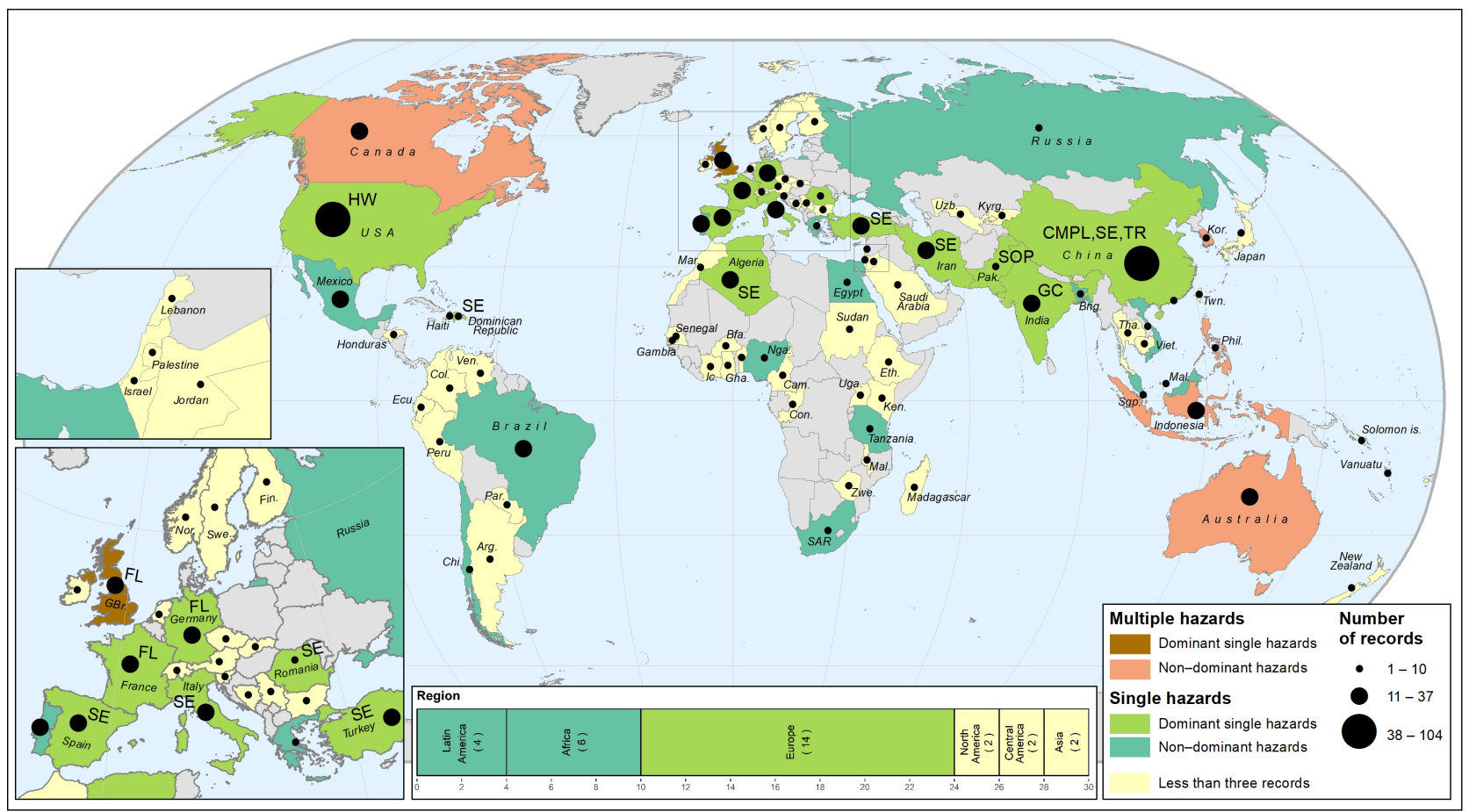

Fig. 5 Typology of countries based on the variability of approaches to vulnerability mapping

proach to vulnerability assessments (Pesaro 2018; see Wisner 2020 for a critical discussion of the 'dividend' terminology in DRR).

In Fig. 5, we distinguished five types of countries (map) and regions-continents (lower strip) according to the integration of hazards within the individual studies and the dominance of certain hazards. At the primary level, two major types were recognised: countries dominated by singlehazard or multi-hazard studies. We assigned countries to the multi-hazard category if at least $1 / 4$ of the records concerned more than one hazard; the rest were considered single-hazard regions. At the secondary level, two subtypes were distinguished for each type according to the characteristics of the hazards researched for particular countries. For each type, we sought regions where a single hazard was dominant by following three rules: (i) the hazard appeared in $>50 \%$ of all records, (ii) the hazard appeared more often than $1.5 *$ IQR (interquartile range), and (iii) there should be more than two records for a particular hazard. The last (fifth) type referred to regions with less than three records, for which it was impossible to draw conclusions about single- or multi-hazard dominance.

Even at the country scale, there was a prevalence of single-hazard approaches to vulnerability assessments, with a negligible difference between cases exhibiting dominance of a particular hazard and those where various hazards were assessed. Regional differences indicated certain relationships to the most threatening events, especially in Europe, where north-western and central European countries accounted for a majority of studies on floods, whereas studies focusing on vulnerability to seismic hazards were most frequent in southern Europe. Only four countries (Australia, Canada, Indonesia, and the United Kingdom) recorded a clear prevalence of multi-hazard vulnerability assessments, of which only the United Kingdom displayed the dominance of a particular hazard (floods) next to the multi-hazard studies. The fifth case falling within the preferred multi-hazard approach represented global vulnerability studies which not related to a particular country(ies).

\subsection{Data in vulnerability assessments}

In this section, we analyse patterns across studies of individual hazard types in terms of preferred data source. Since transparent lists of data sources were most frequently present in spatially explicit studies (67\% of all 707 studies) that used cartographical representations ( $44 \%$ of all studies), we focused only on this subset of records $(n=310)$. Almost $60 \%$ of these studies used data from their own research to elaborate the vulnerability assessments, while 


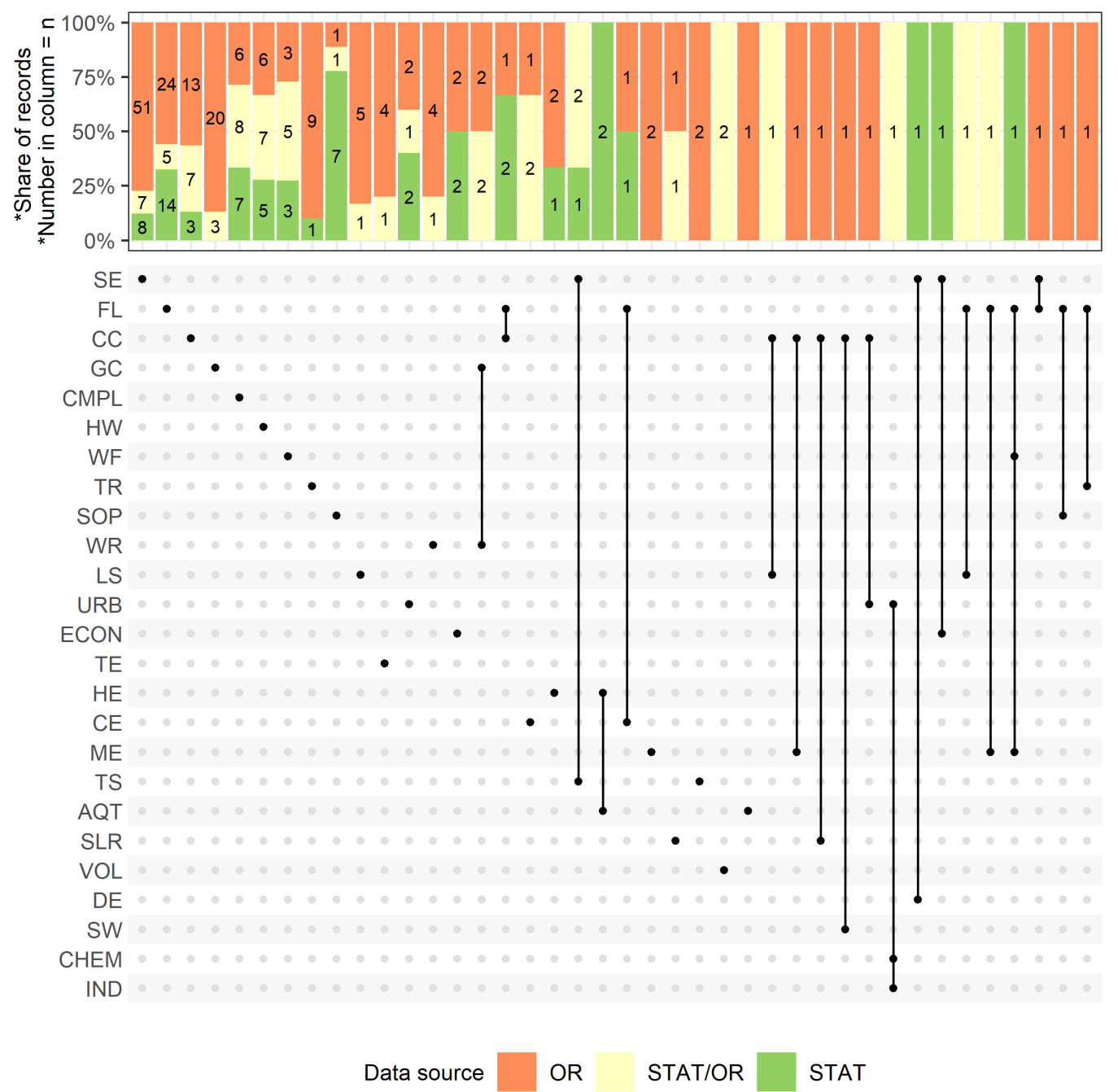

Fig. 6 Frequency of preferred data sources for vulnerability assessments of individual and combined hazards in studies with cartographic representation. Note: OR - original data obtained or derived by authors of the studies; STAT - statistical data from official authorities. See Supplement 1 for explanation of hazard abbreviations. For visual clarity, the figure displays only 40 columns accounting for 289 of the 310 records.

statistical and combined data were both employed in $20 \%$ of cases.

The own research (i.e. studies based on original data collected by their authors) was mostly based on manual identification of features under threat using remotely sensed data, GIS overlay analysis of different datasets, physical models of the built environment, and field inventories and surveys of social perception of hazards (both interviews and questionnaires). The statistical data mostly exploited the potential of official national, regional, and municipal statistics and censuses, and therefore aimed at demographic, educational, and economic characteristics of the population and assets. The preference towards certain data source produced some patterns, but these were not significant due to small number of records. Of the most frequently represented hazard types, seismic and groundwater contamination were predominantly assessed by the study authors' own research (Fig. 6). The need to employ original data surveys results from the general lack of (and uncertainties in) detailed information about built (seismic hazard) and natural (groundwater contamination) environments in official sources. On the other hand, studies focusing on the vulnerability of the social environment (floods, climate change, heatwaves) more often used official datasets, sometimes also complemented with study-specific field surveys of data on social and physical vulnerability.

This pattern confirms previous claims regarding a persistent lack of integrative vulnerability assessments, while providing an explanation with critical implications for future research. In this re- 
spect, the persisting scarcity of research assessing vulnerability to multiple hazards seems to result from a bias towards considering physical or social vulnerabilities independently, representing a peculiar conceptual understanding of vulnerability and the status of respective research agendas across disciplines. This duality means that integrative assessments are also hampered by the various data sources employed. Moreover, the issues of transferability of established vulnerability indicators and their effects on the complexity of vulnerability assessments must be noted. Statistical data are among the best available sources, thus reducing time demands for vulnerability assessments. The transferability of vulnerability indicators is limited, however, as the variety of population indicators available for different regions and countries differs significantly. This can be well-documented with regional alterations to the Social Vulnerability Index (SoVI; Cutter et al. 2003; Huang et al. 2015; di Girasolle \& Cannatella 2017) reflecting the different availability of variables in national and regional statistics. In addition, studies tend to reduce the range of variables or generalise the vulnerability factors with increasing coverage of vulnerability assessments, from more diverse and robust at a local level (Cutter et al. 2008 to generalised at a global scale (Kok et al. 2016). Finally, common statistical data (sets of indicators) would tend to reduce the current emphasis on cultural embeddedness and contextual factors determining vulnerabilities (Kuhlicke et al. 2011; Bankoff et al. 2015). Field research data, in turn, provide high-resolution information, often with a unique complexity, but their acquisition is time-demanding and therefore usually limited to local case studies. Another issue concerning the use of field research data is their limited temporal scale or flexibility. In contrast to statistical data, field data are usually collected once or occasionally and are therefore unable to capture the dynamic temporal nature of vulnerabilities (cf. Kelman 2018).

\subsection{Spatially explicit approaches and vulnerability maps}

Spatially explicit vulnerability assessments that take advantage of cartographic visualisations represent the basis for designing plans and procedures for various phases and actions within DRR (e.g. Emergency Operation Planning). Although non-cartographic works remain fundamental as they allow re-evaluation of the vulnerability concepts and addressing reasons of vulnerability, studies that include cartographic representation of vulnerability assessments are among the major research outcomes that may draw the attention of the practitioners (cf.Wisner 2016 for the 'longterm' and 'short-term' application of the vulnerability concept).

Focusing only on the 693 studies in the reduced database, $67 \%(n=467)$ had spatially explicit vulnerability assessments (Fig. 7). Of these, 64\% $(n=301)$ also included cartographic representation of the data, indicating that cartographic representation is among the primary aims of spatially explicit vulnerability assessments. The maps in the reviewed studies were presented either as an example (part of the overall area under study) or for the whole study area. In the former case, the descriptions of the cartographic representations did not allow detailed assessments of the reasons for presenting only part of the study area. Importantly, neither the purpose for presenting the maps or recommended guidelines for their careful interpretation and use were provided in many studies. This creates the potential for extreme flexibility for subjective interpretations (cf. Kelman 2018), uses, and misuses of maps in vulnerability studies. The absent interpretation guidelines also challenge legitimacy of the vulnerability maps. For the areas and communities, which are depicted as vulnerable without an additional explanation of the roots of vulnerability, may be stigmatized as inherently poor, weak, or otherwise incapable of vulnerability reduction. This finally leads to biased assumptions about the particular areas and communities (Fekete 2012).

Within single-hazard studies, maps were most commonly present for heat waves $(75 \%$ of all heat waves studies), groundwater contamination hazards (59\%), and seismic hazards (56\%). Multihazard vulnerability studies with maps were significantly underrepresented, accounting only for 32 cases (less than $5 \%$ of 693 studies). If present, these maps visualised integrated vulnerabilities for causerelated hazards, such as groundwater contamination and water resources, or seismic hazards and tsunamis.

The publication record for different hazard types and their combinations, as well as the preferred data sources and share of spatially explicit assessments, revealed clear differences in the review. Therefore, the goal of our final analyses was to identify the typical coverage and resolutions of vulnerability maps. Such an analysis could reveal how hazard type affects map coverage and resolution via the preferred data type and therefore help to better understand the aforementioned barriers to vulnerability assessments integrating different hazard 


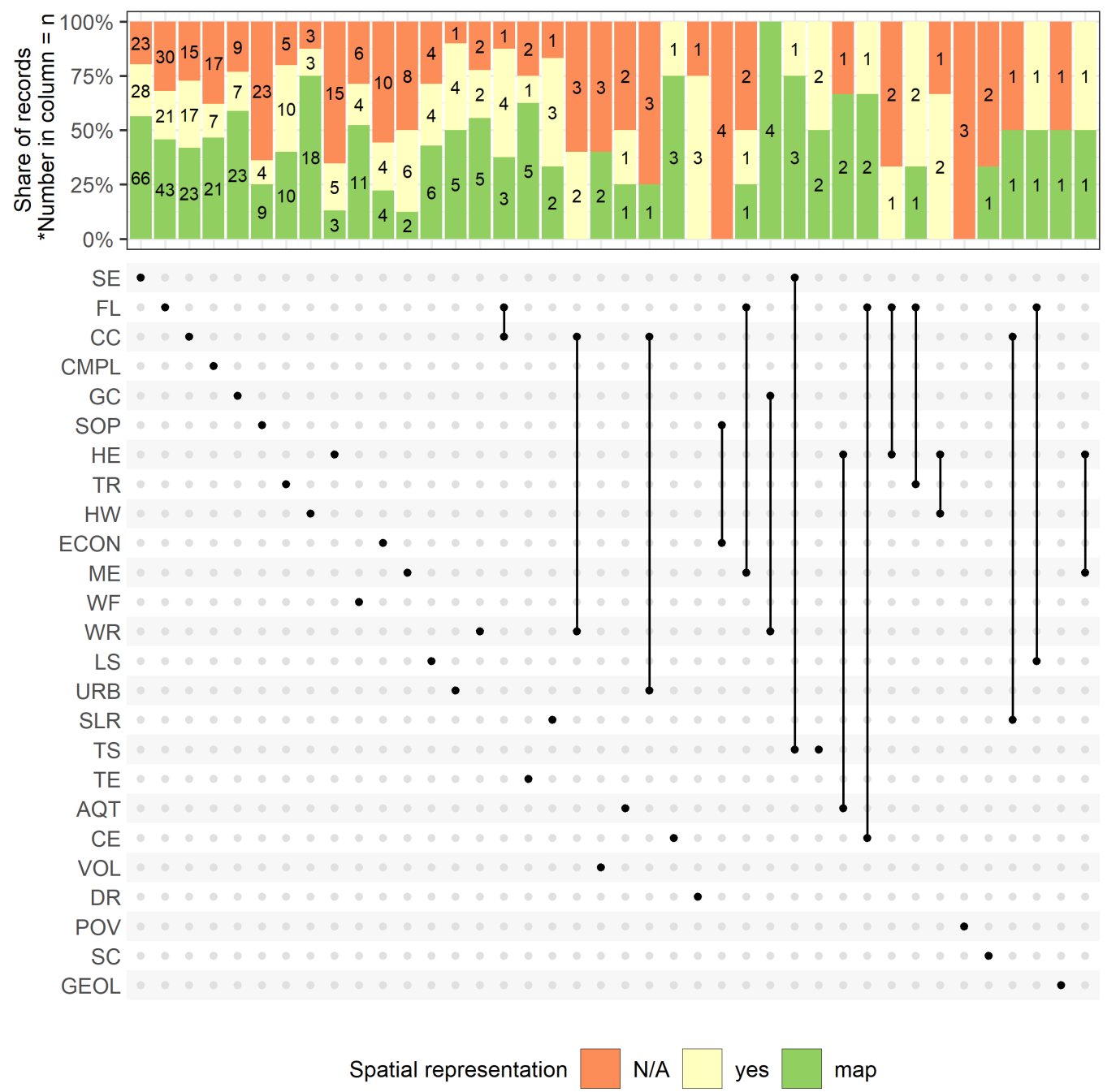

Fig. 7 Number of spatially explicit vulnerability assessments and number of studies presenting cartographic representation, grouped according to hazard types or combinations. Note: yes - the study engages with a spatial assessment of vulnerability; map - the study engages with a spatial assessment of vulnerability and includes a map; N/A - any spatially explicit component is not available in the study. See Supplement 1 for explanation of hazard abbreviations.

types. Fig. 8 presents a matrix of two map variables - coverage and resolution - with the frequency distribution of single-hazard studies. The spatial coverage of maps ranged from continents to blocks of buildings, with country-wide, regional, and cityscale assessments being most frequent. Countrywide and regional assessments were characteristic for climate change, floods, heat waves, and sociopolitical hazards, whereas seismic hazards dominated city-scale maps, followed by floods and other hazards. Depending on spatial coverage, there was also diversity in map resolution. At the city scale, most seismic maps assessed vulnerability for blocks of buildings derived from physical models of construction and damage curves. In contrast, flood maps at the city scale rarely used the fuzzy or block of buildings resolution due to data unavailability, although dasymetric methods have been used to successfully used to overcome this barrier (Nelson et al. 2015).

These results comply with and confirm the previously discussed diversification of vulnerability assessments into at least two major themes: (i) geological and geomorphological studies (mostly seismic hazards) with their own data surveys at a detailed scale and with a lack of links to other hazards, and (ii) other studies (mostly atmospheric hazards and social-political hazards) with primarily statistical data at a municipal, regional, and country scale, with occasional efforts to integrate multiple hazards. 


\section{S sciendo}

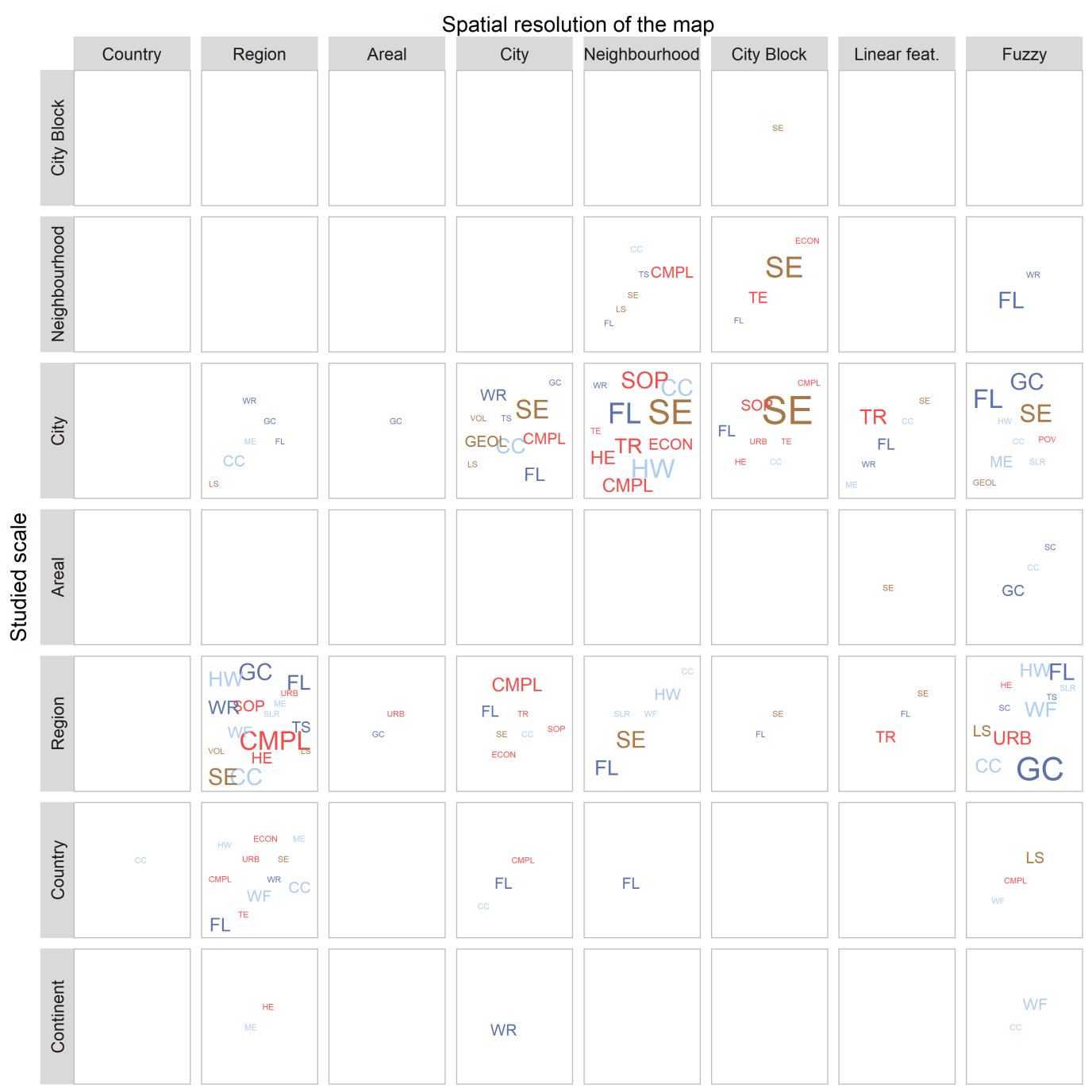

Fig. 8 Typical spatial coverage (vertical axis) and spatial resolution (horizontal axis) of vulnerability maps for hazard types. See Supplement 1 for explanation of hazard abbreviations.

\section{Conclusions}

The ongoing shift towards vulnerability-centred studies in DRR has resulted in multiple reasons to re-assess disasters as complex and dynamic processes preconditioned by political, sociocultural, economic, and environmental characteristics with manifest profound spatial variations. In this review, we analysed 707 academic papers (published between 1988 and 2018), aiming at vulnerability assessments with a particular focus on spatially explicit approaches in urban settings in order to reveal how scholarly publishing reflects the theoretical debate regarding the aforementioned DRR challenges. Our results show that there remains an alarming scarcity of assessments integrating vulnerabilities to multiple hazards. We interpret this scarcity as a result of disciplinary and epistemic traditions within the disciplines engaged in vulnerability assessments. These are underpinned by the very nature of the hazards under study and manifested by preferred approaches towards a hard distinction between physical or social vulnerabilities, and by prioritising certain types of data sources for vulnerability assessments. The data used in the reviewed studies only partly reflect the dynamic and culturally constrained character of vulnerabilities and disasters. Such preferences then proliferate to the spatial coverage and resolution of vulnerability maps, altogether hampering attempts at integrated vulnerability assessments. Finally, although cartographic representations have become frequent components of vulnerability studies as a result of widespread geoinformation tools, our results found vague rationalisations for the pre- 
sentation of such maps, and a lack of guidelines for the interpretation of uncertainties and the use of maps as decision-support tools.

\section{Acknowledgement}

The authors thank the Operational Programme Research, Development and Education of the Czech Republic for financing the project Smart City-Smart Region-Smart Community (grant number: $\quad$ CZ.02.1.01/0.0/0.0/17 048/0007435) that led to the present paper.

\section{Footnotes}

${ }^{1}$ Such a focus is not meant to insinuate that the rural population, which often lacks financial resources and power to initiate institutional change to cope with disasters, deserves less attention. Our focus derives from the scope of the ongoing research project aimed to provide integrative vulnerability assessments for an urban setting.

${ }^{2}$ This distinction was only for improved orientation as most of these hazards exhibited interconnectedness in their causes as well as exacerbation of their impacts (e.g. landslides can be triggered by human alteration to terrain, flood frequencies may be affected by climate change and their magnitudes by floodplain alteration, and smoke and dust veil tracks following industrial accidents may be affected by actual weather).

${ }^{3}$ These studies focused on establishing complex indicators of social vulnerability rather than integrating different hazards and risks.

${ }^{4}$ Most studies exploring vulnerability to climate change did not explicitly focus on integrative assessments to various climate change-related hazards, but rather used climate change as a terminological framework and mostly explored temperature variations over time.

\section{References}

Adger N (2006) Vulnerability. Global Environmental Change 16: 268-281.

Alexander DE (1995) A survey of the field of natural hazards and disaster studies. In: Carrara A, Guzzetti F (eds) Geographical information systems in assessing natural hazards. Advances in Natural and Technological Hazards Research 5. Springer, Dordrecht, pp. 1-19.

Alexander D (2002) Principles of emergency planning and management. Terra, Hertfordshire.

Baker VR (2017) Interdisciplinarity and the Earth sciences: transcending limitations of the knowledge paradigm. In: Frodeman R, Thompson Klein J, Pacheco RCS (eds) The Oxford handbook of interdisciplinarity. Oxford University Press, Oxford, pp. 88-100.

Bankoff G, Cannon T, Krüger F, Schipper ELF (2015) Introduction: exploring the links between cultures and disasters. In: Krüger F, Bankoff G, Cannon T, Orlowski B, Schipper ELF (eds) Cultures and disasters: understanding framings in disaster risk reduction. Routledge, London, pp. 1-16.
Berg C, Emran MS (2020) Microfinance and vulnerability to seasonal famine in a rural economy: evidence from Monga in Bangladesh. The B.E. Journal of Economic Analysis \& Policy, in press. DOI: https://doi.org/10.1515/bejeap-2018-0359

Bojórquez-Tapia LA, Cruz-Bello GM, Luna-González L, Juárez L, Ortiz-Pérez MA (2008) V-DRASTIC: Using visualization to engage policymakers in groundwater vulnerability assessment. Journal of Hydrology 373(1-2): 242-255.

Burgman M (2005) Risks and decisions for conservation and environmental management. Cambridge University Press, Cambridge.

Burton I, Kates RW, White GF (1978) The environment as hazard. New York, Oxford University Press.

Burton C, Rufat S, Tate E (2018) Social vulnerability. Conceptual foundations and geospatial modeling. In: Fuchs S, Thaler T (eds) Vulnerability and resilience to natural hazards. Cambridge University Press, Cambridge, pp. 53-81.

Chatterjea K (2011) Severe wet spells and vulnerability of urban slopes: case of Singapore. Natural Hazards 56: 1-18.

Cutter S (1996) Vulnerability to environmental hazards. Progress in Human Geography 20: 529-539.

Cutter SL (2018) Compound, cascading, or complex disasters: what's in a name?. Environment: Science and Policy for Sustainable Development 60(6): 16-25.

Cutter SL, Boruff BJ, Shirley WL (2003) Social vulnerability to environmental hazards. Social Science Quarterly 84(2): 242-261.

Cutter SL, Barnes L, Berry M, Burton C, Evans E, Tate E, Webb $\mathrm{J}$ (2008) A place-based model for under-standing community resilience to natural disasters. Global Environmental Change 18, 598-606.

de Ruiter MC, Ward PJ, Daniell JE, Aerts JCJH (2017) Review Article: A comparison of flood and earthquake vulnerability assessment indicators. Natural Hazards \& Earth System Sciences 17: 1231-1251.

di Girasole EG, Cannatella D (2017) Social vulnerability to natural hazards in urban systems. An application in Santo Domingo (Dominican Republic). Sustainability 9: 2043.

Dostál P (2008) Changing geographical systems and risk processes: general considerations. In: Dostál P (ed) Evolution of geographical systems and risk processes in the global context. P3K, Prague, pp. 15-36

EEA (2010) Mapping the impacts of natural hazards and technological accidents in Europe An overview of the last decade. EEA Technical Report No 13/2010. Copenhagen, European Environment Agency.

EFDRR (2013) How does Europe link DRR and CCA. Working Paper. EFDRR.

EM-DAT (2018) Natural disasters 2018. Centre for Research on the Epidemiology of Disasters, Brussels.

Fekete A (2012) Spatial disaster vulnerability and risk assessments: challenges in their quality and acceptance. Natural Hazards 61(3): 1161-1178.

Gunes A, Kovel J (2000) Using GIS in emergency management operations. Journal of Urban Planning and Development 126(3): 136-149.

Hall O, Duit A, Caballero LNC (2008) World poverty, environmental vulnerability and population at risk for natural hazards. Journal of Maps 4(1): 151-160.

Hewitt K (1983) Interpretations of calamity from the viewpoint of human ecology. Allen and Unwin, London. 


\section{sciendo}

Horák J, Ivan I (2020) Applied GIS in the context of smart regions and cities. GeoScape 13(2): 86-87.

Hore K, Kelman I, Mercer J, Gaillard JC (2018) Climate change and disasters. In: Rodríguez H, Donner W, Trainor JE (eds) Handbook of disaster research. Springer, New York, pp. 145-159.

Huang J, Su F, Zhang P (2015) Measuring social vulnerability to natural hazards in Beijing-Tianjin-Hebei Region, China. Chinese Geographical Science 25: 472-485.

Kasperson RE, Kasperson JX, Dow K (2001) Vulnerability, equity, and global environmental change. In: Kasperson JX, Kasperson RE (eds) Global environmental risk. Earthscan, Sterling, VA, pp. 247-272.

Kelman I (2008) Critique of some vulnerability and resilience papers. Version 2, 17 November 2008 (Version 1 was 7 July 2008). Available at: Downloaded from < http://www.islandvulnerability.org/docs/vulnrescritique.pdf>

Kelman I (2015) Climate change and the Sendai Framework for Disaster Risk Reduction. International Journal of Disaster Risk Science 6: 117-127.

Kelman I (2018) Lost for words amongst disaster risk science vocabulary? International Journal of Disaster Risk Science 9: 281-291.

Kelman I, Gaillard JC, Mercer J (2015) Climate change's role in disaster risk reduction's future: beyond vulnerability and resilience. International Journal of Disaster Risk Science 6: 21-27.

Kok M, Lüdeke M, Lucas P, Sterzel T, Walther C, Janssen P, Sietz D, de Soysa I (2016) A new method for analysing socio-ecological patterns of vulnerability. Regional Environmental Change 16: 229-243.

Kuhlicke C, Scolobig A, Tapsell S, Steinführer A, De Marchi B (2011) Contextualizing social vulnerability: findings from case studies across Europe. Natural Hazards 58: 789-810

Kuhlicke C, Seebauer S, Hudson P, Begg C, Bubeck P, Dittmer C, Grothmann T, Heidenreich A, Kreibich H, Lorenz DF, Masson T, Reiter J, Thaler T, Thieken AH, Bamberg S (2020) The behavioral turn in flood risk management, its assumptions and potential implications. WIREs Water 7(3): e1418.

Leaning J, Guha-Sapir D (2013) Natural disasters, armed conflict, and public health. New England Journal of Medicine 369: $1836-1842$.

Lewis J (2012) The Good, The Bad and The Ugly: disaster risk reduction (DRR) versus disaster risk creation (DRC). PLoS 4 e4f8d4eaec6af8.

Lechtenfeld T (2013) Mapping vulnerability: extending static poverty maps for vietnam. In: Klasen S, Waibel H (eds) Vulnerability to poverty. Palgrave Macmillan, London.

Lins-de-Barros FM (2017) Integrated coastal vulnerability assessment: a methodology for coastal cities management integrating socioeconomic, physical and environmental dimensions - Case study of Região dos Lagos, Rio de Janeiro, Brazil. Ocean \& Coastal Management 149: 1-11.

Liverman DM (1990) Drought impacts in Mexico: climate, agriculture, technology, and land tenure in Sonora and Puebla. Annals of the Association of American Geographers 80: 49-72.

Moher D, Liberati A, Tetzlaff J, Altman DG, The PRISMA Group (2009) Preferred reporting items for systematic reviews and meta-analyses: The PRISMA Statement. PLoS Med 6(7): e1000097.

Munene MB, Swartling AG, Thomalla F (2018) Adaptive governance as a catalyst for transforming the relationship between development and disaster risk through the Sendai Framework? International Journal of Disaster Risk Reduction 28: 653-663.

Munich Re (2017) Natural Disasters 2017 - Analyses, Assessments, Positions. TOPIC GEO. Munich.

Nelson KS, Abkowitz MD, Camp JV (2015) A method for creating high resolution maps of social vulnerability in the context of environmental hazards. Applied Geography 63: 89-100.

OECD (2019) Regional outlook 2019: Leveraging megatrends for cities and rural areas. Organization for Economic Cooperation and Development.

Oliver-Smith A, Alcántara-Ayala I, Burton I, Lavell A (2016) Forensic Investigations of Disasters (FORIN): a conceptual framework and guide to research. Integrated Research on Disaster Risk, ICSU, Beijing. Available at: http://www.irdrinternational.org/wp-content/uploads/2016/01/FORIN-21.pdf

Pesaro G (2018) The economic impacts of natural hazards: lessons learnt from PDNA International damage assessment project implemented in Haiti after the earthquake of 2010. In: Petrillo A, Bellaviti (eds) Sustainable urban development and globalization. Springer, Cham, pp. 321-332.

Stehlíková M, Raška P, Bláha JD (2017) Household labelling for flash flood emergency management (Chrastava town,Northern Czechia). Journal of Maps 13: 747-754.

R Core Team (2017) R: A language and environment for statistical computing. R Foundation for Statistical Computing, Vienna, Austria. Available at: <https://www.R-project.org>

Rashed T, Weeks J (2003) Assessing vulnerability to earthquake hazards through spatial multicriteria analysis of urban areas, International Journal of Geographical Information Science 17(6): 547-576.

Raška P (2019) Contextualizing community-based landslide risk reduction: an evolutionary perspective. Landslides 16(9): 1747-1762.

Raška P, Dostál P (2017) Evolution of disaster relief law under multiple transformations: progressive learning or walking in a circle?. Environmental Science Policy 76: 124-130.

Rufat S, Tate E, Burton CG, Maroof AS (2015) Social vulnerability to floods: review of case studies and implications for measurement. International Journal of Disaster Risk Reduction Volume 14: 470-486.

Sarewitz D., Pielke R Jr, Keykhah M (2003) Vulnerability and risk: some thoughts from a political and policy perspective. Risk Analysis 23: 805-810.

Sawada Y, Bhattacharyay M, Kotera T (2019) Aggregate impacts of natural and man-made disasters: a quantitative cmparison. International Journal of Development and Conflict, Gokhale Institute of Politics and Economics 9(1): 43-73.

Singha P, Shankar V, Sinha P, Vijhani A, Pahuja N (2018) Vulnerability assessment of urban road network from urban flood. International Journal of Disaster Risk Reduction 28: 237-250.

Thonicke K, Bahn M, Lavorel S, Bardgett RD, Erb K, Giamberini M, Reichstein M, Vollan B, Rammig A (2020) Advancing the understanding of adaptive capacity of social-ecological Systems to absorb climate extremes. Earth's Future 8: e2019EF001221.

Turner BL II., Kasperson RE, Matson PA, McCarthy JJ, Corell RW, Christensen L, Eckley N, Kasperson JX, Luers A, Martello ML, Polsky C, Pulsipher A, Schiller A (2003) A framework for vulnerability analysis in sustainability science. Proceedings of the National Academy of Sciences US 100: 8074-8079.

UN (2018) The World's Cities in 2018. Data booklet. United Nations. Available at: < https://www.un.org/en/events/citiesday/assets/pdf/the_worlds_cities_in_2018_data_booklet.pdf $>$ 


\section{S sciendo}

UNDRR (2015) Sendai Framework for Disaster Risk Reduction 2015-2030. United Nations, Geneva.

UNISDR (2017) Vulnerability. UNISDR Terminology. Available at: https://www.preventionweb.net/terminology White G, Kates $\mathrm{R}$, Burton I (2001) Knowing better and losing even more: the use of knowledge in hazards management. Environmental Hazards 3: 81-92.

Wisner B (2016) Vulnerability as concept, model, metric and tool. In: Oxford research encyclopaedia: natural hazards.
Oxford University Press, Oxford, pp. 1-51. Available at: < https://oxfordre.com/naturalhazardscience/view/10.1093/acrefore/9780199389407.001.0001/acrefore-9780199389407-e-25>

Wisner B (2020) Five years beyond Sendai-can we get beyond frameworks? International Journal of Disaster Risk Science, in press. DOI: 10.1007/s13753-020-00263-0

WMO (2019) Statement on the state of the global climate in 2018. WMO-No. 1233, World Meteorological Organization, Geneva. 